\title{
Microstructure, Texture, Mechanical and Ballistic Properties Correlation of a Hot Rolled and Peak Aged AA-7017 Alloy Plate at Surface and Centre
}

\author{
Pradipta Kumar Jena' ${ }^{1}$, Kandikattu Siva Kumar ${ }^{1}$, Rajiv Kumar Mandal2², Ashok Kumar Singh ${ }^{1}$ \\ ${ }^{1}$ Defence Metallurgical Research Laboratory, Hyderabad, India \\ ${ }^{2}$ Department of Metallurgical Engineering, IIT (BHU), Varanasi, India \\ Email: *pradipta_rrlb@rediffmail.com
}

How to cite this paper: Jena, P.K., Kumar, K.S., Mandal, R.K. and Singh, A.K. (2017) Microstructure, Texture, Mechanical and Ballistic Properties Correlation of a Hot Rolled and Peak Aged AA-7017 Alloy Plate at Surface and Centre. Materials Sciences and Applications, 8, 992-1013.

https://doi.org/10.4236/msa.2017.813073

Received: August 25, 2017

Accepted: December 8, 2017

Published: December 11, 2017

Copyright $\odot 2017$ by authors and Scientific Research Publishing Inc. This work is licensed under the Creative Commons Attribution International License (CC BY 4.0).

http://creativecommons.org/licenses/by/4.0/

\begin{abstract}
The present work describes microstructure, texture, mechanical and ballistic properties correlation of a hot rolled and peak aged AA-7017 alloy plate at surface and centre. Both the microstructures and textures are different on the surface and centre of the plate. The surface of the plate shows recrystallized grains and a weak over all texture. The centre of the plate displays elongated grains and a sharp texture. Tensile properties, hardness and impact toughness are evaluated at surface and centre of the plate. It is observed that strength and hardness is high at centre, whereas ductility and impact toughness is more at the surface. Ballistic properties of the plate at centre and surface are measured by impacting against two different $7.62 \mathrm{~mm}$ deformable projectiles. The plates impacted on the surface shows better ballistic resistance. Ballistic performance of the plate at surface and centre has been correlated with the microstructure, texture and mechanical properties.
\end{abstract}

\section{Keywords}

Ballistic Performance, AA 7017 Alloy, Microstructure, Texture, Mechanical Property, Ballistic Property, Anisotropy

\section{Introduction}

Ballistic impact research has been focused on developing lighter materials which can resist the threat successfully. High strength aluminium alloys have drawn attention for protection against ballistic impact applications due to their high strength to weight ratio and energy absorption capability. A large number of 
references are available in literature on ballistic behavior of high strength aluminum alloys [1]-[10]. These alloys can give equally good or even better ballistic protection per unit weight compared to those of the traditional steels [8] [11] [12]. The heat treatable aluminum alloys such as Al-Cu base AA 2219, AA 2519, Al-Zn base AA 7017, AA 7039, AA 7020, AA 7055, AA7075 have been explored for ballistic application [1] [10] [13] [14] [15] [16]. Among these, the aluminium7017 alloy is an $\mathrm{Mg}-\mathrm{Zn}$ precipitation-hardened alloy and is one of the commonly used armour material in the form of rolled plates.

Materials for ballistic application are generally used in the form of rolled plates and produced by thermo-mechanical processing that consists of hot/cold working, solution treatment and aging. Thermomechanical processing is likely to introduce specific microstructure as well as texture at different stages such as hot/cold deformation and heat treatments. This in turn governs the anisotropy in mechanical properties. Development of microstructures during thermomechanical processing depends on the rolling temperature, extent of rolling reduction and subsequent cooling. It has been reported that the microstructure and texture may be inhomogeneous through the thickness of the rolled plates due to the inhomogeneity of the deformation caused during rolling [17] [18] [19], and the non uniformity of the recrystallization that occurs during the heat treatment [20]. The hot rolled microstructures further get modified during solution treatment and subsequent aging. Two types of anisotropy namely, in-plane and through-thickness, have been reported in rolled products [21]. The thin sheet products typically display in-plane anisotropy i.e. variation in mechanical properties in different sample directions. Thick plate products, on the other hand have through-thickness anisotropy exhibiting different mechanical properties from centre to surface of the plate. Consequently, these variations must be taken into account while designing and making components for ballistic application.

As a result of through-thickness anisotropy, hot rolled and peak aged AA 7017 alloy plates display different microstructures and associated grain orientations across the thickness of the plate. This in turn exhibits different mechanical and ballistic properties. Present work, thus focuses on the understanding of the ballistic behavior of a $70 \mathrm{~mm}$ thick AA 7017 alloy plate by impacting on its surface and centre and correlating the ballistic results with microstructures and textures. Related damage and deformation microstructural patterns of the material after ballistic impact have also been analyzed. In addition, a comparative study of the mechanical properties has been carried out to explain the ballistic behavior.

\section{Experimental Procedure}

AA 7017 alloy plates of $70 \mathrm{~mm}$ thickness were received from Alcan International (UK) in hot rolled and peak aged condition. The analysed chemical composition of alloy is given in Table 1. Microstructure characterization of the plate was carried out at surface and centre of the plate. The specimens were prepared following standard metallographic techniques used for Aluminium and its alloys. All 
Table 1. Analyzed chemical composition of the alloy.

\begin{tabular}{cc}
\hline Material & Chemical Composition \\
\hline $\mathrm{Al}-7017$ & $4 \%-5.2 \% \mathrm{Zn}, 2 \%-3 \% \mathrm{Mg}, 0.35 \% \mathrm{Si}, 0.35 \% \mathrm{Cr}, 0.45 \% \mathrm{Fe}, 0.2 \% \mathrm{Mn}$, balance Al \\
\hline
\end{tabular}

Table 2. Analyzed compositions of the precipitates by EPMA.

\begin{tabular}{|c|c|c|c|c|c|c|c|c|}
\hline Weight \% & $\mathrm{Mg}$ & $\mathrm{Al}$ & $\mathrm{Si}$ & $\mathrm{Cr}$ & $\mathrm{Mn}$ & $\mathrm{Fe}$ & $\mathrm{Zn}$ & Total \\
\hline Bright & 0.32 & 72.91 & 0.46 & 0.19 & 11.85 & 12.38 & 1.33 & 99.43 \\
\hline Gray & 63.16 & 3.68 & 29.79 & 0.04 & 0.03 & 0.04 & 3.01 & 99.75 \\
\hline
\end{tabular}

the samples were etched using Keller's reagent $\left(5 \mathrm{ml} \mathrm{HNO}_{3}, 3 \mathrm{ml} \mathrm{HCl}, 2 \mathrm{ml} \mathrm{HF}\right.$ and $190 \mathrm{ml}$ water) to reveal the microstructure. The microstructures were examined in optical and scanning electron microscopes (OM and SEM). Chemical compositions of precipitates were analyzed using Electron Probe Micro Analyzer (EPMA: Cameca SX100) and results are given in Table 2. The through-thickness bulk hardness of the plate was measured using an AFFRI Vickers hardness tester at a load of $5 \mathrm{Kg}$.

The X-ray diffraction (XRD) studies of bulk samples were carried out using a Philips 3020 diffractometer (Philips, The Netherlands) with $\mathrm{CuK} \alpha$ radiation equipped with a graphite monochrometer. $25 \times 15 \times 5 \mathrm{~mm}$ size samples were cut from the surface and centre regions of the plate and were metallographically polished for the XRD and texture measurements. An inel G3000 texture goniometer coupled with curved position sensitive detector with $\mathrm{CuK} \alpha$ radiation was employed for texture measurement using Schultz back technique [22]. Three incomplete pole figures $\{111\},\{200\}$ and $\{220\}$ were measured from surface and centre of the $70 \mathrm{~mm}$ thick plate. An oscillation stage was employed with $20 \mathrm{~mm}$ specimen translation to increase the measured area. From the pole figure data, the complete orientation distribution function (ODF) plots are obtained. The results are presented as ODF plots of constant $\varphi_{2}$ section with iso-intensity contours in the Euler space defined by three Euler angles $\left(\varphi_{1}, \Phi, \varphi_{2}\right)$ and typical $\beta$ fibre.

Samples of $150 \mathrm{~mm} \times 150 \mathrm{~mm} \times 70 \mathrm{~mm}$ size were cut from a big plate. Then the plates were sliced at the mid thickness as shown in Figure 1. Out of these sliced samples three samples were impacted against deformable projectiles with the top surface of the starting plate (surface) facing the projectile. Three other samples were impacted against deformable projectiles with the centre plane of the starting plate (centre) facing the projectile. Ballistic experiments were performed in a small arms range. The schematic of the testing arrangement is shown in Figure 2. The gun was mounted on a rigid mount. The target holding fixture was located in the tunnel at a distance of $10 \mathrm{~m}$ from the gun. All the plates were impacted by a projectile at $0^{\circ}$ angle of impact. Two different types of deformable projectiles were used for the ballistic testing. One projectile was having complete lead core, whereas the other projectile was having a soft steel core. The nominal and actual diameters of the projectiles were 7.62 and 6.06 




Figure 1. Schematic representation of the sectioning of the $70 \mathrm{~mm}$ thick plate. The plates were sliced along the dotted lines in the centre into two halves.

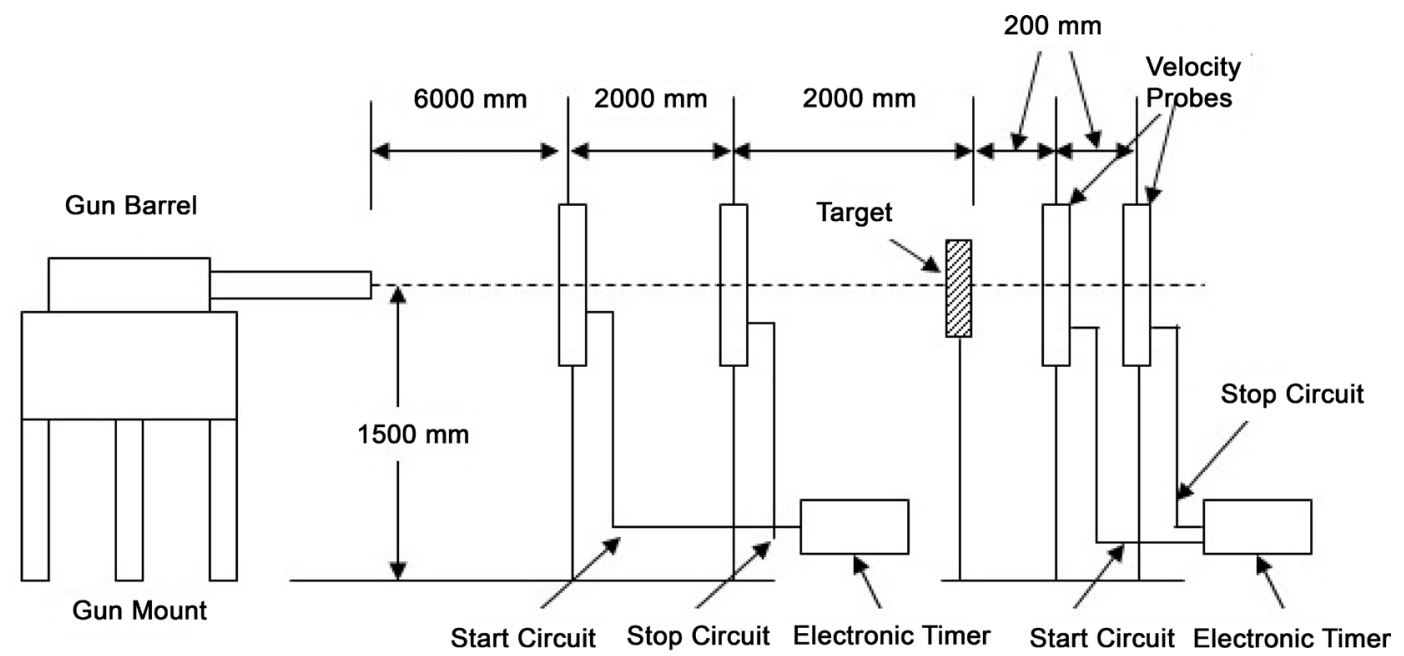

Figure 2. Schematic of ballistic testing set-up.

$\mathrm{mm}$, respectively. The impact velocities of the projectile was measured in each test with the help of two aluminum velocity foil screens by measuring the time interval between the interceptions caused by the projectile running across the aluminum foils which are kept at a fixed distance apart. The measured impact velocity was $840 \pm 15 \mathrm{~m} / \mathrm{s}$. By proper laying of the gun, it was ensured that the centre-to-centre distance between any two impact craters on the plate was at least three times the diameter of the projectile. This is required to avoid the overlapping of plastic deformation zones formed around the crater.

After ballistic testing, these plates were cut into half across the craters and then subjected to standard metallographic procedure to reveal the post ballistic microstructures. Optical microscope was used to observe the microstructure along the path of the projectile. Vickers micro hardness values were obtained adjacent to the crater wall using a Leica micro hardness tester at $50 \mathrm{gm}$ load.

Tensile and Impact samples were machined as per the schematic diagram shown in Figure 3 in order to evaluate the properties of the material at surface and centre of the starting plate. Tensile properties of the material were evaluated at a crosshead speed of $1.0 \mathrm{~mm} / \mathrm{min}$ using an Instron Universal Testing machine (Instron 5500R). Three tensile tests were carried out in accordance with ASTM E8-93 and average values of the tensile properties are reported in the present study. Standard Charpy V-notch (CVN) impact specimens having V-notch of 2 mm depth were prepared for the impact tests. The tests were carried out as per 


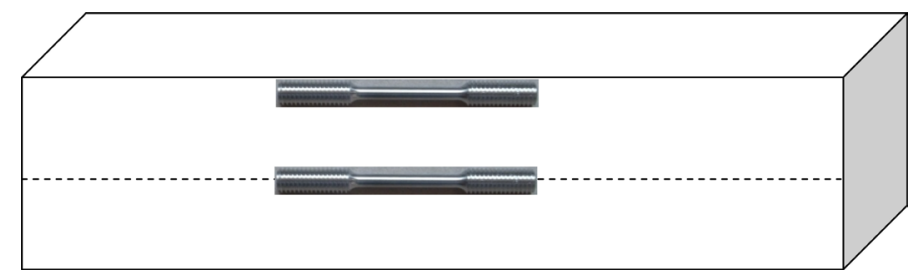

Figure 3. Locations of tensile and Charpy samples taken from $70 \mathrm{~mm}$ thick plate.

the ASTM standards (E23-02a) using the Tinius-Olsen impact-testing instrument. The fracture surfaces of the impact specimens were examined using a LEO scanning electron microscope.

\section{Results}

\subsection{Initial Microstructure}

The optical microstructures of the plate at the surface and centre are shown in Figure 4. This exhibits three distinct features namely grey matrix, white region along grain boundaries and dark precipitates. The white regions reflect the particle simulated nucleated (PSN) recrystallized grains. The recrystallization occurs around intermetallic precipitates due to the presence of larger strains at the interface between precipitates and matrix. The volume fraction of recrystallized grain is comparatively large at the surface in comparison to that of the centre of the plate (Figure 4(a) and Figure 4(b)). The back scattered electron (BSE) image of the plate displays the presence of two types of precipitates with bright and dark contrasts (Figure 5). The analyzed compositions obtained by electron probe micro analyser (EPMA) indicate that these are $\mathrm{Al}_{6} \mathrm{FeMn}$ and $\mathrm{Mg}_{2} \mathrm{Si}$ precipitates (Table 2).

\subsection{Texture Characterization}

The XRD pattern of the alloy shows that the matrix is typical face-centered-cubic (fcc) phase ( $\mathrm{Al}$ matrix, $\mathrm{Fm} \overline{3} \mathrm{~m}$ ) (Figure 6). The lattice constant of the matrix phase is $4.05 \AA$. The textures of the materials at the surface and centre are shown in Figure 7. The overall intensity of texture at the centre is nearly 7 times larger than that of the surface. The major texture components at the surface and centre of the plate are $\left.\left\{\begin{array}{lllll}0 & 1 & 11\end{array}\right\}\left\langle\begin{array}{llll}3 & 11 & 1\rangle\end{array}\right][\mathrm{f}(\mathrm{g})=1.9],\left\{\begin{array}{lll}0 & 1 & 11\end{array}\right\}\left\langle\begin{array}{llll}15 & 11 & 1\rangle\end{array}\right] \mathrm{f}(\mathrm{g})=2.5\right], \begin{cases}0 & 1\end{cases}$

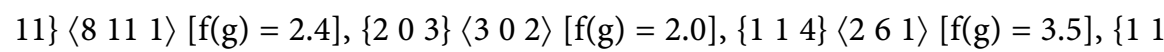
3\} $\left.\left.\left.\left\langle\begin{array}{lll}0 & 3 & 1\rangle\end{array}\right\rangle \mathrm{f}(\mathrm{g})=2.9\right],\left\{\begin{array}{llll}2 & 2 & 1\end{array}\right\}\left\langle\begin{array}{llll}3 & 4 & 2\rangle\end{array}\right] \mathrm{f}(\mathrm{g})=3.3\right],\left\{\begin{array}{llll}1 & 1 & 2\end{array}\right\}\left\langle\begin{array}{lll}1 & 1 & 0\rangle\end{array}\right] \mathrm{f}(\mathrm{g})=3.4\right]$ and $\{0$ $11\}\left\langle\begin{array}{llll}5 & 3 & 3\end{array}\right\rangle[\mathrm{f}(\mathrm{g})=16.4],\left\{\begin{array}{llll}4 & 4 & 1\end{array}\right\}\left\langle\begin{array}{lll}1 & 0 & 4\end{array}\right\rangle[\mathrm{f}(\mathrm{g})=17.5]$, respectively. The intensities $[\mathrm{f}(\mathrm{g})]$ of the texture components are reported as "times random". The corresponding typical $\beta$ fibers of this alloy at centre and surface are shown in Figure 8. The $\beta$ fibre is very weak and homogeneous at the surface while highly inhomogeneous with very high intensity between $\{168\}\langle 211\rangle$ and $\{011\}\langle 211\rangle$ locations.

\subsection{Mechanical Properties}

The engineering stress-strain and true stress-true strain curves for the AA 7017 
plate at surface and centre are given in Figure 9. The average values of yield strength $\left(\sigma_{\mathrm{YS}}\right)$, ultimate tensile strength $\left(\sigma_{\mathrm{UTS}}\right)$ and elongation at the surface and centre are given in Table 3 and Figure 9(c). The impact energy values obtained from Charpy impact test are also given in Table 3 and Figure 9(d). VHN hardness profile of as received plate from surface $\rightarrow$ centre $\rightarrow$ surface is shown in Figure 10. This exhibits a gradual increase and decrease in hardness values from surface to centre and centre to surface, respectively.


Figure 4. Optical microstructures of the normal direction planes taken from (a) surface and (b) centre of the $70 \mathrm{~mm}$ thick plate. 



Figure 5. BSE microstructure taken from the (a) surface (b) centre of plate and (c) BSE microstructure showing white $\left(\mathrm{Al}_{6} \mathrm{FeMn}\right)$ and dark contrast $\left(\mathrm{Mg}_{2} \mathrm{Si}\right)$ precipitates. 




Figure 6. XRD patterns taken from the surface and centre of the $70 \mathrm{~mm}$ thick plate.



Maximum 3.8×random

(a)

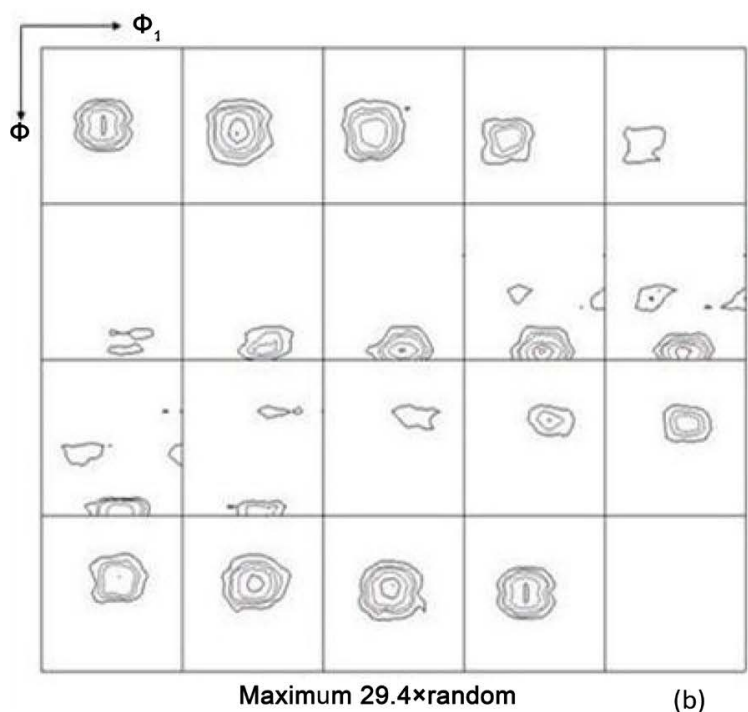

(b)
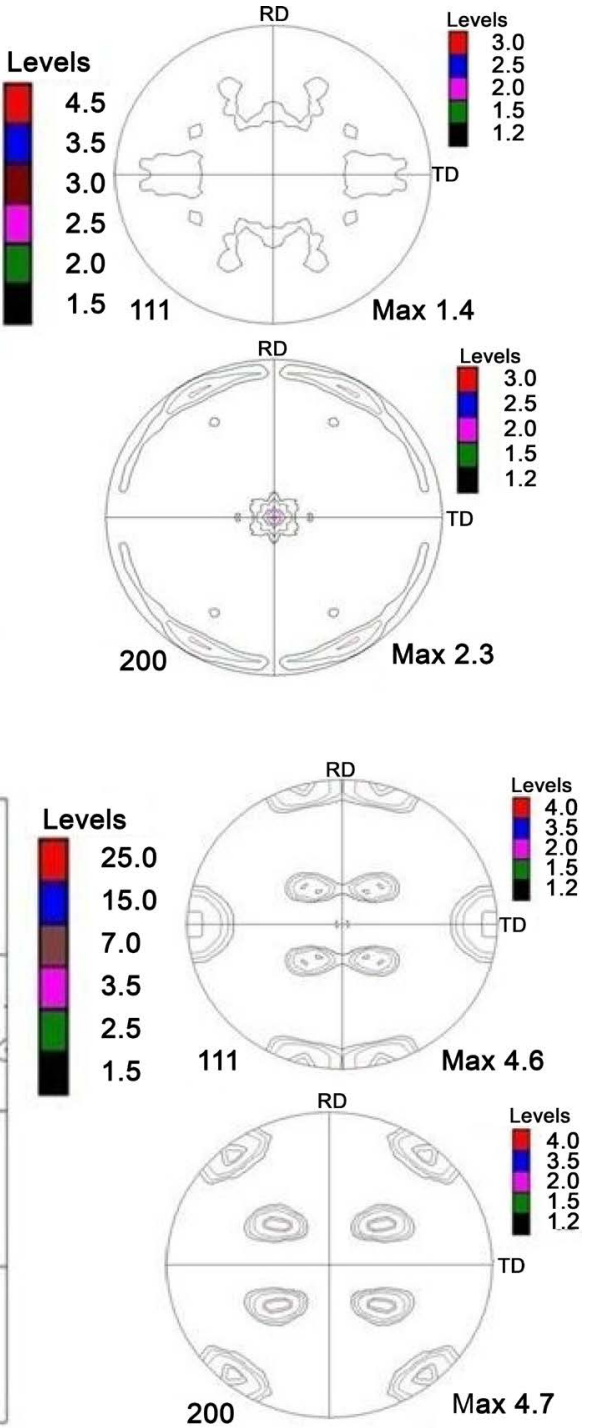

200

Figure 7. Textures of the plate measured from the (a) surface and (b) centre of the $70 \mathrm{~mm}$ thick plate. 


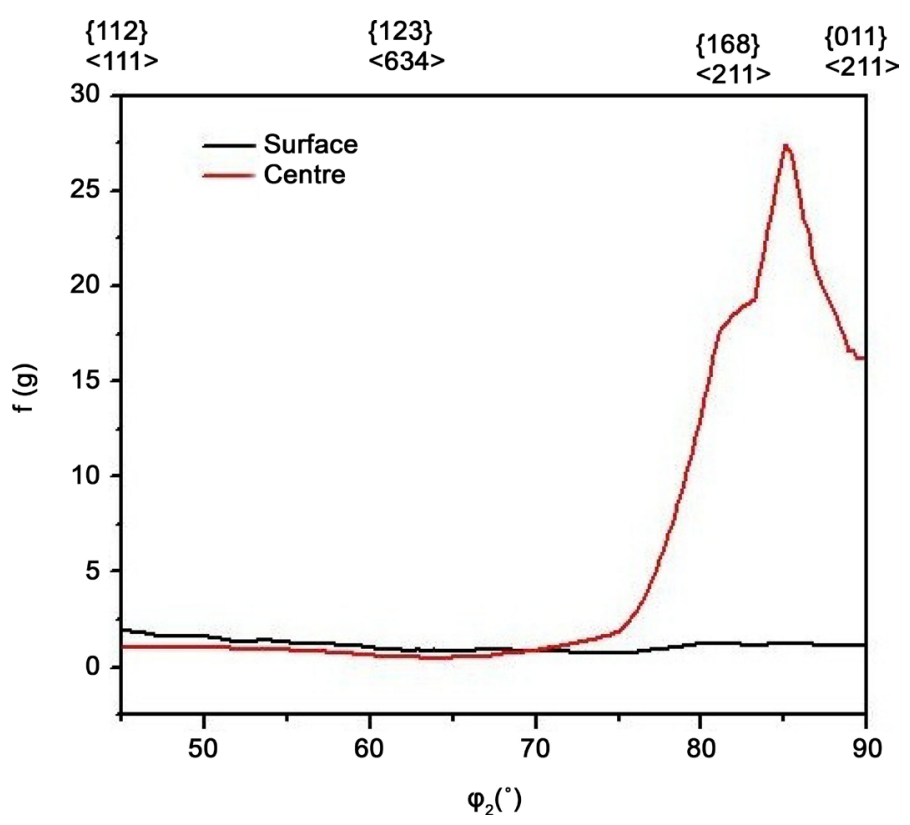

Figure 8. Typical $\beta$ fibres from surface and centre of the plate.



(a)

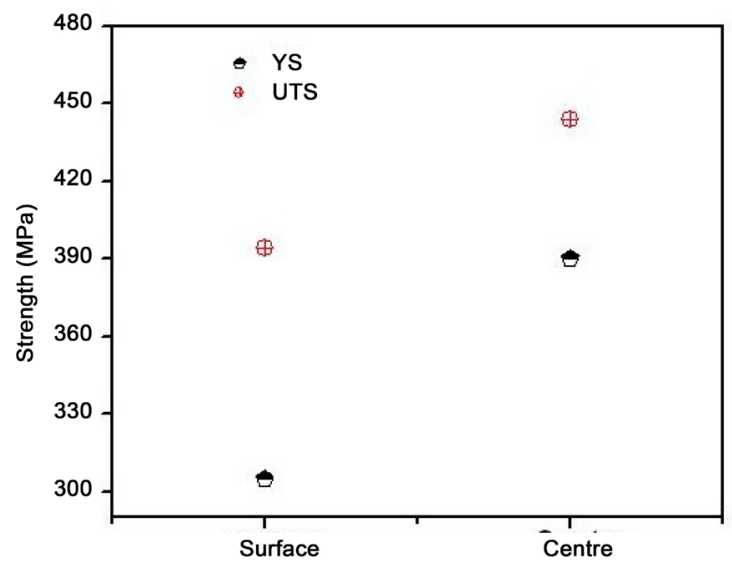

(c)

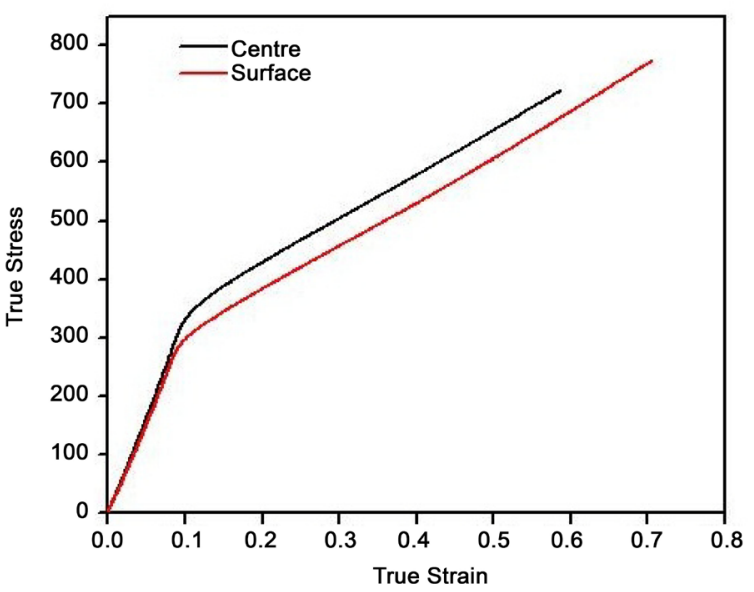

(b)

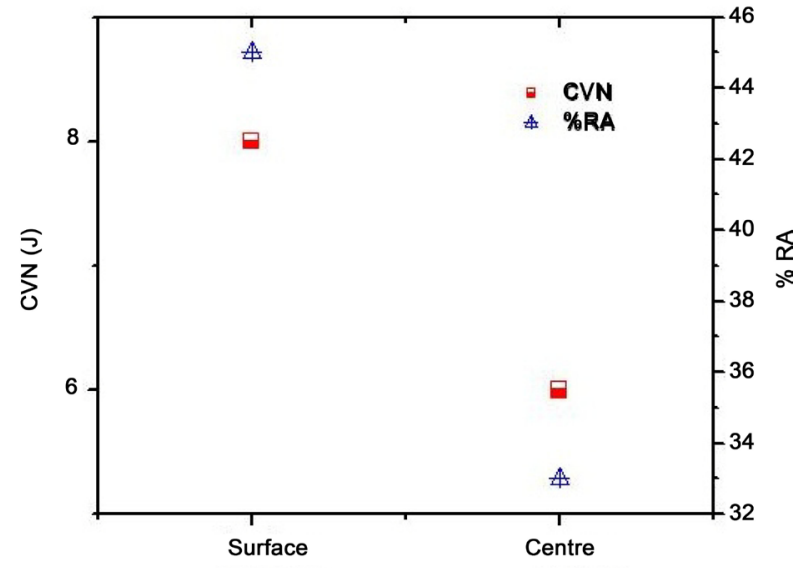

(d)

Figure 9. Tensile properties from the surface and centre of plates: (a) Engineering stress-engineering strain and (b) True stress-true strain curves. (c) YS and UTS at surface and centre and (d) CVN and \%RA at surface and centre. 
Table 3. Mechanical properties of the plate at surface and centre.

\begin{tabular}{ccccc}
\hline Sample location & YS $(\mathrm{MPa})$ & UTS $(\mathrm{MPa})$ & \%RA & CVN $(\mathrm{J})$ \\
\hline Surface & 306 & 394 & 45 & 8 \\
Centre & 390 & 448 & 33 & 6 \\
\hline
\end{tabular}

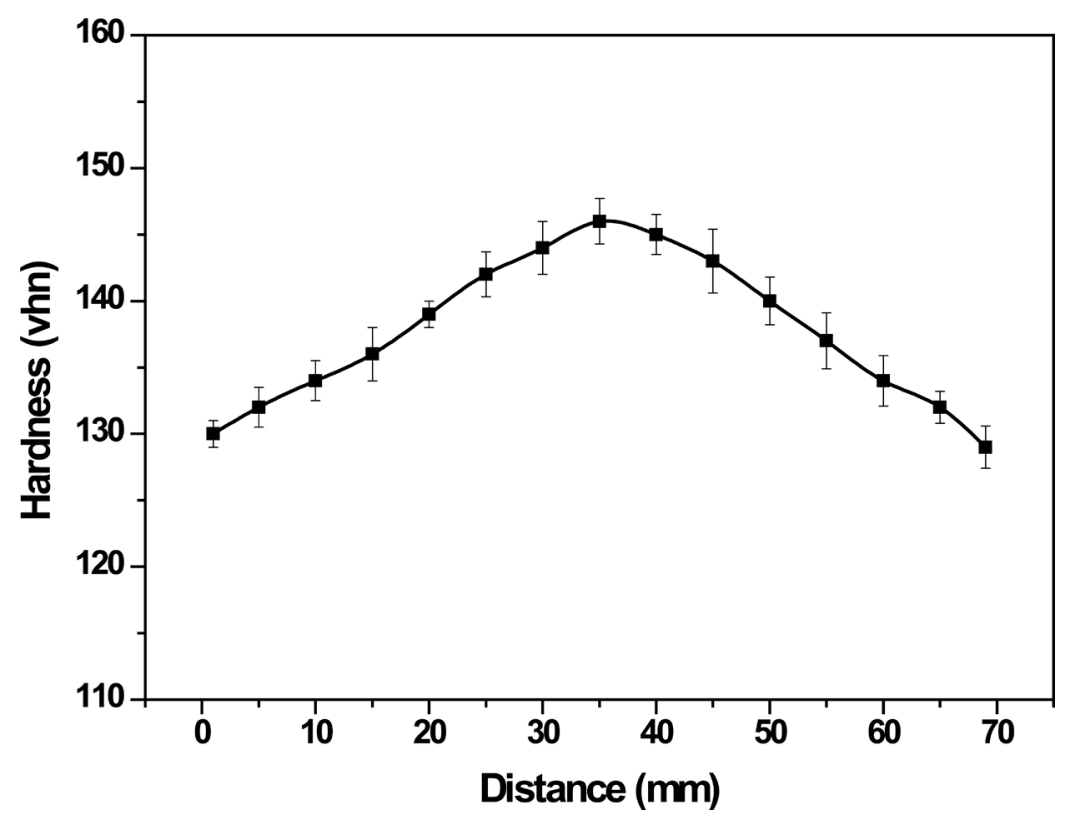

Figure 10. Hardness distribution of the plate along the cross section.

The fracture surfaces of the tensile specimens are quite distinct in samples made from surface and centre of the plate. Both the samples exhibit typical ductile dimples which are fine and shallow at the surface whereas coarse and flattened at the center (Figure 11(a) \& Figure 11(b)). The high magnification BSE fractographs reveal the presence of cracks within and around Fe rich particles (shown by arrow in Figure 11(c)) at the surface while centre sample exhibits these cracks within and around Fe rich particles as well as in the matrix (shown by arrow in Figure 11(d)). The Charpy impact samples exhibit absence and presence of cracks in surface and centre specimens, respectively (Figure 12(a) \& Figure 12(b)). The high magnification BSE features are similar to those of tensile specimens (Figure 12(c) \& Figure 12(d))

\subsection{Ballistic Properties}

Ballistic properties in terms of the depth of penetration (DOP) obtained by impacting lead and soft steel projectiles from surface and centre of the plate are shown in Figure 13. It can be seen that the DOP of plates impacted by both the soft steel and lead projectiles on the centre of the $70 \mathrm{~mm} \mathrm{AA} 7017$ plate is higher than that on the surface. It is also observed that the DOP against the soft steel projectile is higher than the lead projectile. The material flows out to form nice petalling damage patterns for the samples impacted on the surface of the $70 \mathrm{~mm}$ AA 7017 plate (Figure 14(a)). On the other hand, broken petal damage pattern 


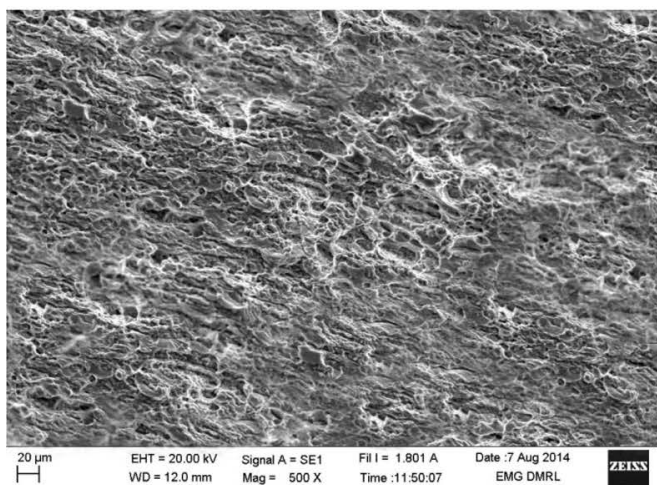

(a)

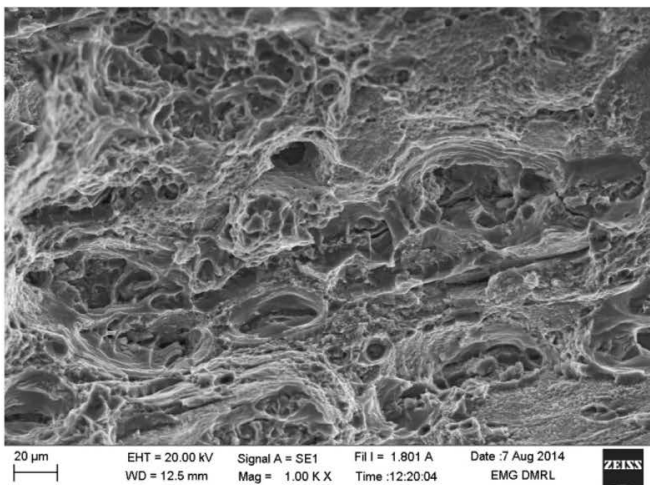

(b)



(c)



(d)

Figure 11. Tensile fractographs: (a) surface and (b) centre specimens Tensile BSE micrographs: (c) surface and (d) centre.
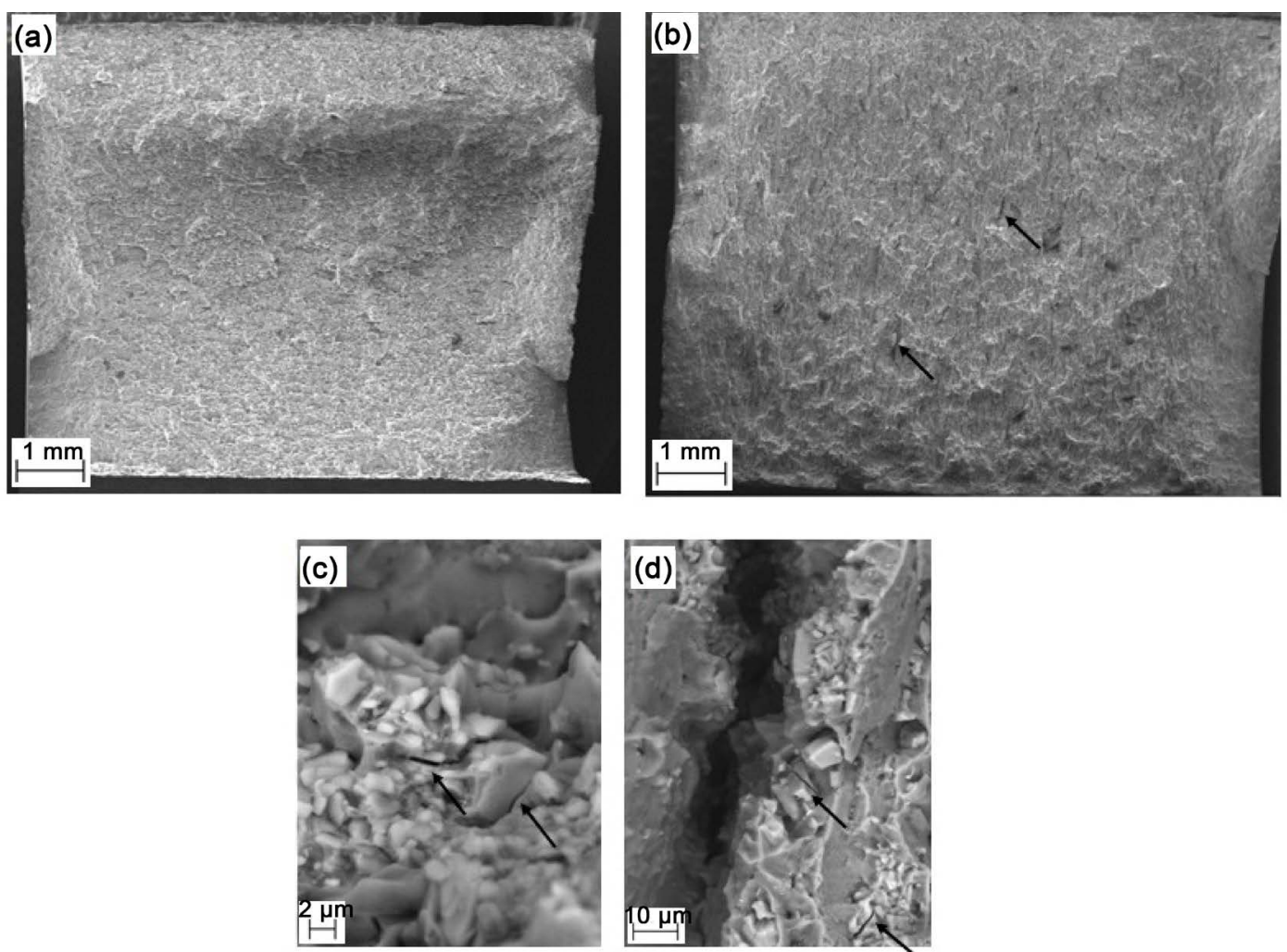

Figure 12. Charpy fractographs: (a) surface and (b) centre specimens Charpy BSE micrographs: (c) surface and (d) centre. 




Figure 13. Ballistic results in terms of depth of penetration against lead and soft steel projectiles.

is observed for the samples impacted on the centre of the $70 \mathrm{~mm}$ AA 7017 plate (Figure 14(b)). The cross sections of the representative post-ballistic impact penetration channels are also included in Figure 14. Macro cracks emanating from the penetration channel are observed for samples impacted on the centre of the $70 \mathrm{~mm}$ AA 7017 plate. No such cracks are observed in the samples impacted on the surface of the $70 \mathrm{~mm}$ AA 7017 plate.

\subsection{Post Ballistic Microstructure Observation}

The impact craters have been examined to observe changes in microstructures after ballistic testing. The microstructures of the target impacted on the surface and centre of the AA 7017 plate against lead and soft steel projectiles are shown in Figures 15-17. The microstructure of the penetration channel formed by the impact of lead projectile on the surface of the AA 7017 plate shows that the material flow lines are severely bent towards the direction of penetration (Figure 15(a)). Only a few shear bands are observed along the penetration channel. Micro cracks are observed originating from the bottom of the crater. The microstructure of the penetration channel formed by impacting on the centre of the 70 mm AA 7017 plates also reveals material flow lines along with many shear bands (Figure 15(b)). The number of the shear bands observed to be decreasing towards the bottom of the penetration channel. As seen in Figure 15(b), the adiabatic shear bands (ASB) are connected with cracks, providing an easy crack propagation path. An enlarged view of ASB induced crack has been shown in Figure 16. Cracks are also observed emanating from the bottom of the penetration channel. 



(a)
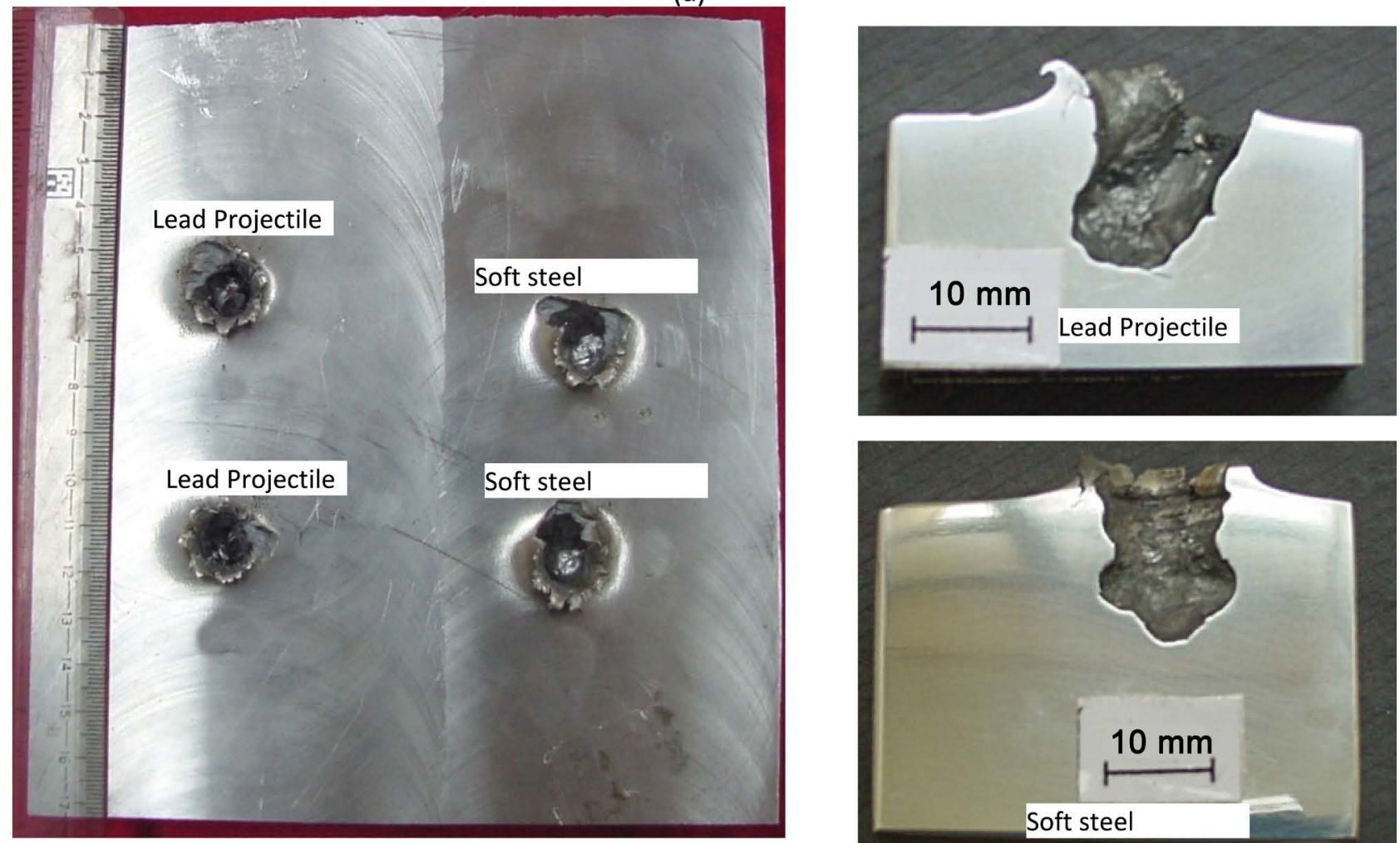

(b)

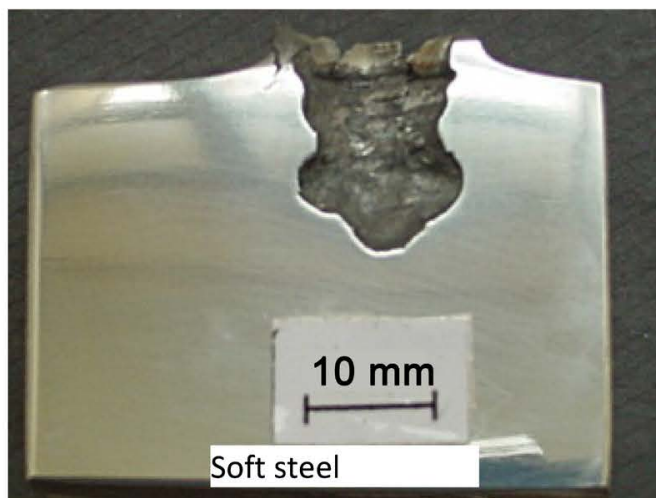

Figure 14. Front view of the (a) surface and (b) centre plates after ballistic testing. Half section views of the respective penetration channels are also included for comparison of penetration channel after ballistic testing. 


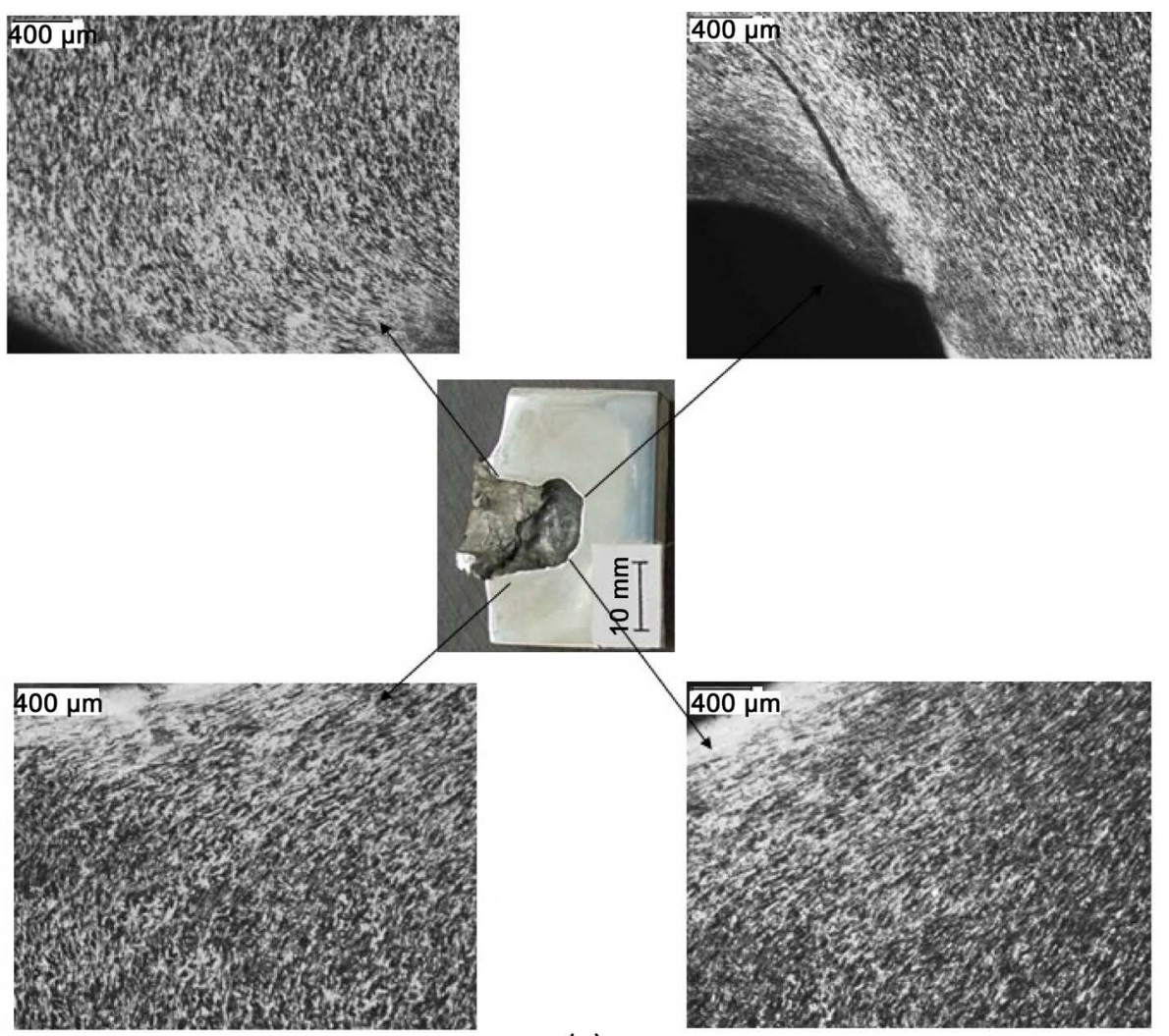

(a)
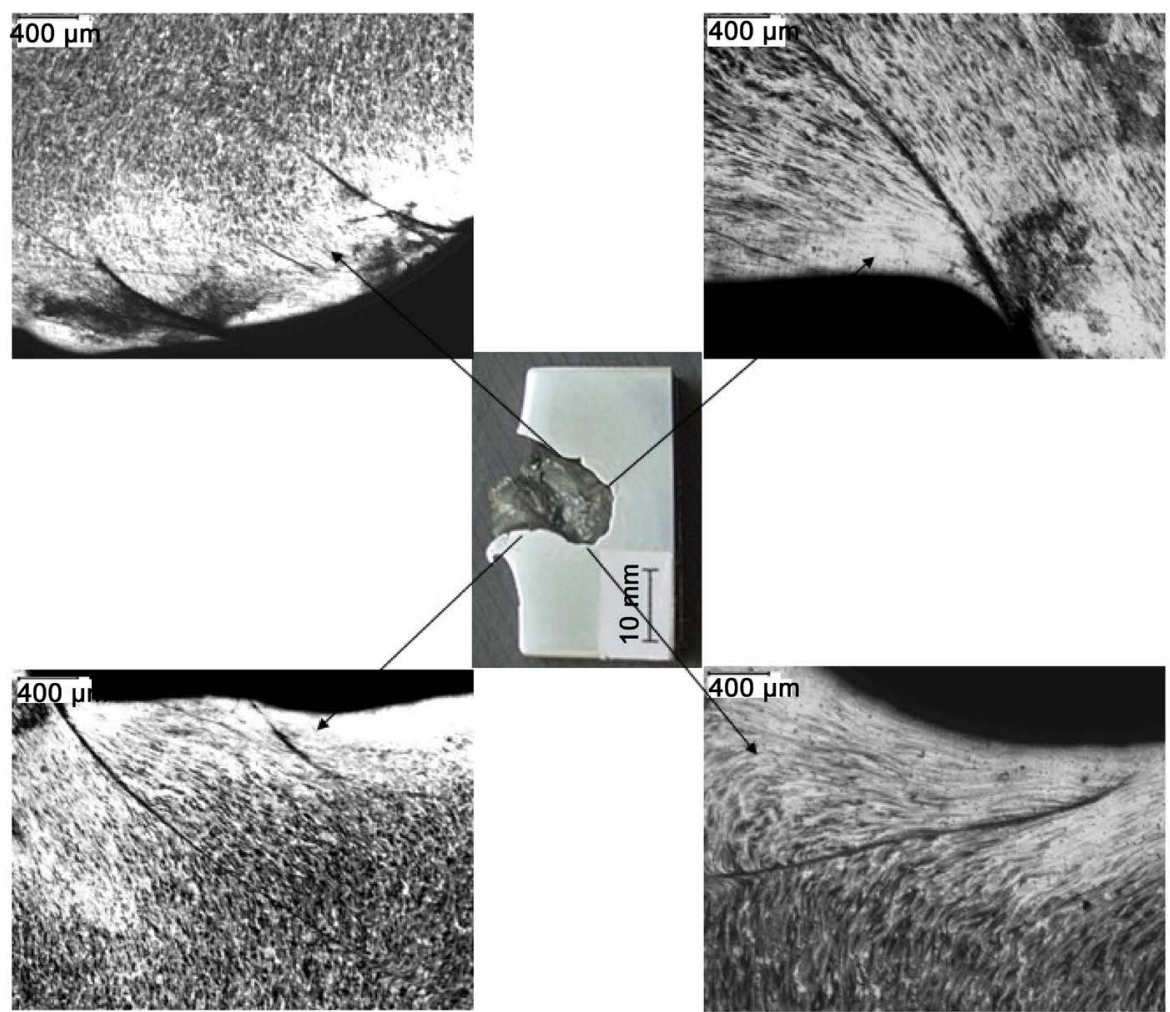

(b)

Figure 15. Post ballistic microstructures along the penetration channel impacted by lead projectile. (a) surface (b) centre. 


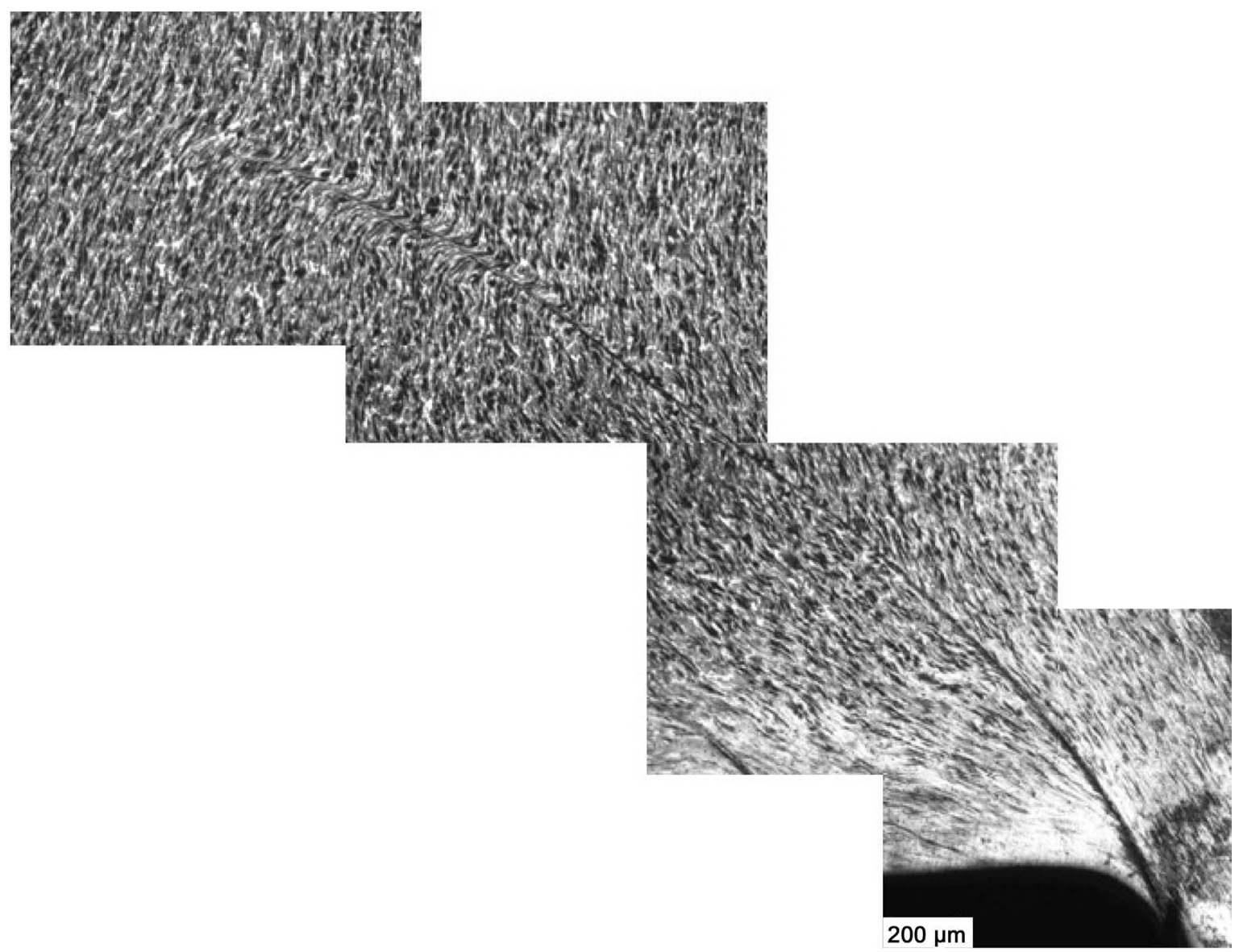

Figure 16. Montage of post ballistic microstructure from the centre showing adiabatic shear bands leading to crack.

The microstructure of the penetration channel formed by the impact of soft steel projectiles on the surface of the $70 \mathrm{~mm}$ AA 7017 plates displays that the maximum deformation is observed at the entry of the projectile (Figure 17(a)). Very few shear bands are seen in the microstructures. A less severe material flow is observed at the bottom of the penetration channel. The penetration channel microstructure of the centre shows severe material deformation at the entry of the projectile (Figure 17(b)). Similar to the lead projectile impacted microstructures as mentioned above, large numbers of shear bands are observed along the length of the penetration channel. Micro cracks are seen emanating from the bottom of the penetration channel.

\subsection{Post Ballistic Micro-Hardness Measurements}

In order to examine the deformation process, distribution of micro Vickers hardness is measured adjacent to the bottom of penetration channel wall created by impact of lead projectiles. Figure 18 summarizes the distribution of hardness along the horizontal direction away from the penetration channel. There is an increase in hardness of all the target plates adjacent to the crater wall compared to the original hardness of the plate. There is a steady increase in the hardness values followed by a gradual decrease in hardness. The region of increase in 



(a)

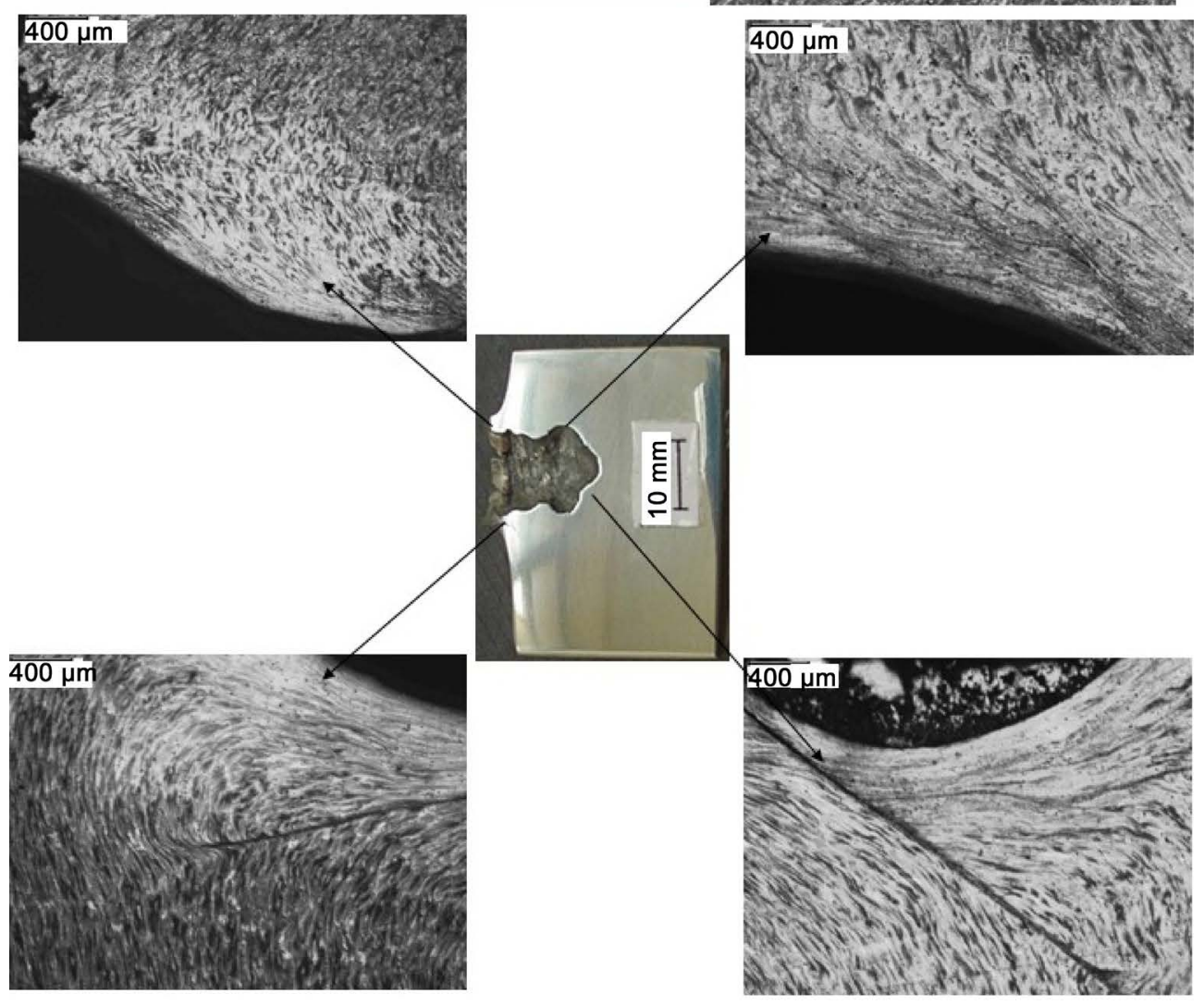

(b)

Figure 17. Post ballistic microstructures along the penetration channel impacted by soft steel projectile (a) surface (b) centre. 

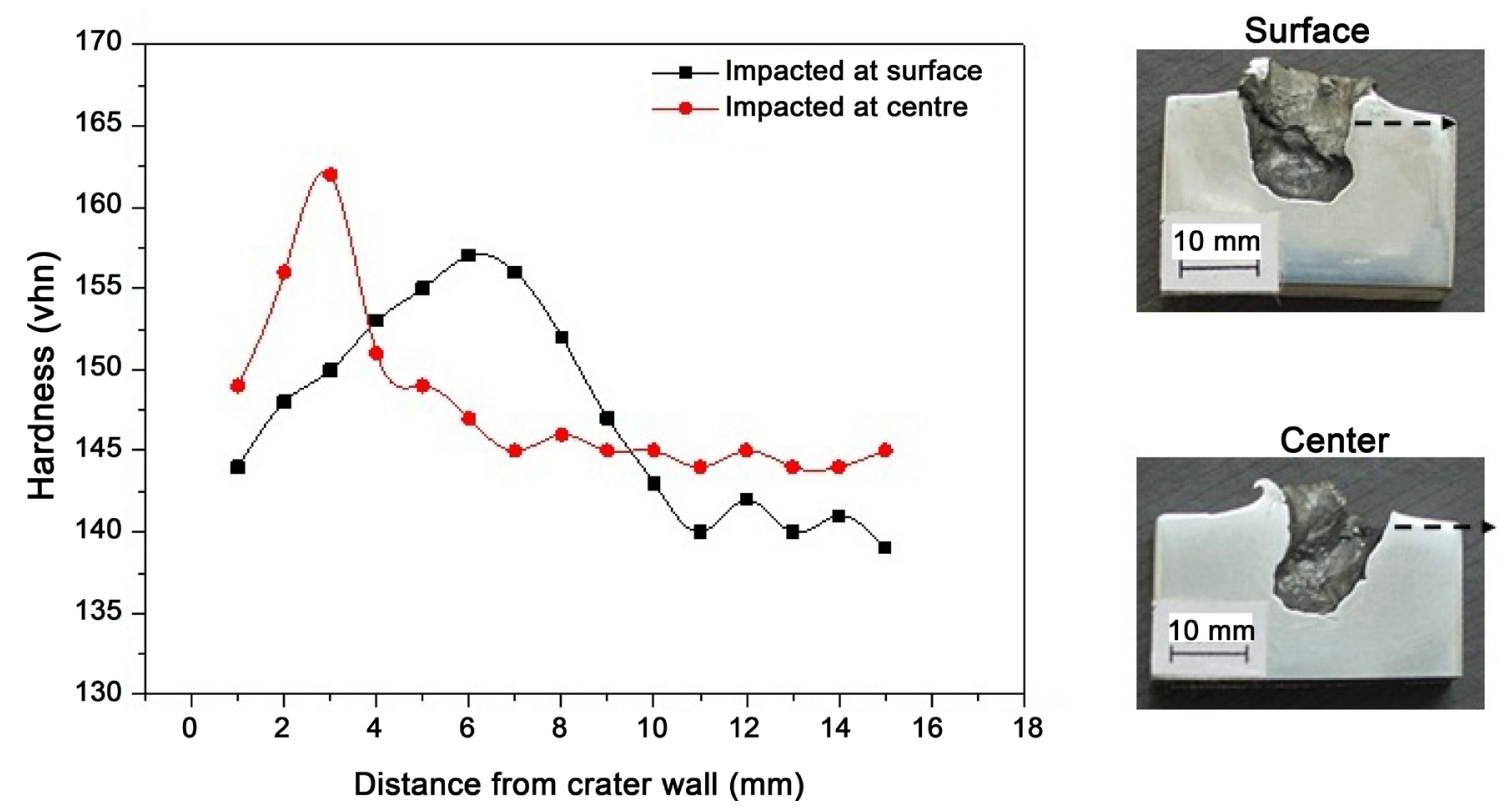

Figure 18. Post ballistic micro-hardness measurements adjacent to the penetration channel wall.

hardness for the surface impacted targets is more than the targets impacted at the initial centre of the $70 \mathrm{~mm} \mathrm{AA} 7017$ plate. In case of the front face impacted targets, the peak in the hardness curve is seen at a distance of about $6 \mathrm{~mm}$ from the bottom of the penetration channel. For the targets impacted at the centre of the plate, the peak hardness is observed at a distance of about $3 \mathrm{~mm}$ from the entrance point of projectile.

\section{Discussion}

The results from the optical microscopy clearly reflect a difference in microstructure at the surface and the centre of the plate. The relatively large volume fraction of recrystallized grains at the surface can be attributed to three factors. These are: i) temperature gradients produced through the work piece created by heat transfer between the rolls and the work piece, ii) strain gradients created by friction between the rolls and the work piece and iii) redundant deformations contribute to this non-uniform microstructure [23]. The recrystallization in present alloy has occurred around the prior deformed grains, wherein the precipitation of $\mathrm{Al}_{6}(\mathrm{FeMn})$ and $\mathrm{Mg}_{2} \mathrm{Si}$ occurs. This in turn contributes to PSN. It is to be noted that the these precipitates are more finely distributed at the centre than that of surface of the $70 \mathrm{~mm} \mathrm{AA} 7017$ plate (Figure 5(a), Figure 5(b)). This can again be attributed to temperature as well as strain gradient as mentioned above. It has been reported that the small dispersed particles in the matrix retard recrystallization rates through exerting a drag force on migrating grain or subgrain boundaries and preventing the nucleation of recrystallization [24]. This also explains the observation of less recrystallization at centre portion of the plate.

Both the XRD patterns from surface and centre of the plate exhibit different 
intensity ratios which are dissimilar to typical powder patterns of Al. This clearly indicates the presence of different texture at surface and centre of the plate. The overall intensity of ODF at the centre is more than seven times higher from the surface. The texture components observed at the surface are either recrystallisation component or located near recrystallisation components. This also reflects that the associated cooling rates after hot rolling is probably not sufficient to produce stable recrystallisation texture. On the other hand, the texture at the centre is quite sharp and close to typical Bs component. The corresponding $\beta$ fibre also supports this observation. Therefore, the difference in texture at the surface and centre of the plate can therefore, be attributed to the stored energy, which drives the recrystallisation process. This is much higher at the surface than that the centre.

It is observed that the mechanical properties also illustrate anisotropy at surface and centre. There is substantial difference in strength at centre than that at surface. The strength is usually dependent on both the texture and the microstructure, especially grain shape. The yield strength can generally be related to the critical resolved shear stress (CRSS) by an equation of the type [23]:

$$
\sigma_{y}=\Delta \sigma_{g b}+M \tau_{\text {tot }}
$$

where $\Delta \sigma_{g b}$ is the strength due to the grain shape, $M$ the Taylor factor which depends on texture and $\tau_{\text {tot }}$ the CRSS of the grains.

In the present study, centre of the plate shows more elongated grains than the surface. This can be attributed to relatively larger fraction of recrystallization at the surface than the centre. As mentioned above, recrystallization occurs in present alloy due to PSN. The recrystallised grains are equiaxed and the large fraction of recrystallized grains at the surface of the plate also reduces the aspect ratios of unrecrystallized grains (Figure 4). As a result, different aspect ratios of grains at the surface and centre of the plate result in different mechanical properties such as $\sigma_{\mathrm{YS}}, \sigma_{\mathrm{UTS}}$, bulk hardness, ductility and Charpy impact energy values. The difference is maximum in yield strength. It has been mentioned that the most affected property due to presence of texture is yield strength but the results of the present study reflect that the other properties are also equally influenced [24].

As mentioned above, the yield strength contributed from the grain shape, i.e. $\Delta \sigma_{g b}$ is higher in the centre than in the surface. The texture is more than seven times sharper at the centre than at the surface, which has lead to higher $M$ value in the centre. Thus, due to the effects of both grain shape and texture, the centre of the plate displays large value of yield strength. As strength and toughness values are inversely proportional to each other, the centre of the plate with high strength shows lower ductility and impact toughness.

The difference in ductility and impact energy at surface and centre of the plate can also be explained from their respective fracture surfaces (Figure 13 \& Figure 14). As mentioned above, cracks are formed within and around the Fe rich precipitates at the surface as well as centre of the plate for both tensile and Charpy 
broken samples. However, formation of cracks in the matrix at centre of the plate can be corroborated with a high intensity texture component located between $\{168\}\langle 211\rangle$ and Bs components. It has been mentioned that only four slip systems are activated for a material with an ideal Brass texture compressed along the short transverse direction [25]. That clearly indicates the presence of limited number of active slip systems associated with Bs component. This has introduced an inhomogeneous deformation during ballistic impact at centre of the plate. As a result, cracks are appeared in the matrix of the centre of the plate. On the other hand, cracks in matrix are absent at the surface due to moderate texture.

Presence of sharp texture in the centre portion of the plate can also be correlated with the presence of large fraction of shear bands at the centre of ballistically evaluated plates. The misorientations among neighboring grains are relatively less at the centre due to presence of sharp texture. This reduces the effectiveness of the grain boundaries as a barrier to slip, which can easily propagate through the grain boundary into neighboring grains [25]. As a result, a large fraction of shear bands are present at the centre of the plate.

For better ballistic performance of any armor material, it is essential that it should be able to absorb as much energy of the projectile as possible in a homogenous manner [26] [27]. Energy absorption in armor material takes place by plastic deformation, which can be inferred from the post-ballistic damage patterns, microstructures and mirco-hardness observations adjacent to the penetration channel. Nice petalling damage pattern observed on surface of the $70 \mathrm{~mm}$ AA 7017 plate after ballistic impact indicates the better ductility and toughness of the target. It also points out that the impact energy is getting transmitted to the adjacent regions effectively. Broken petal damage pattern observed at the centre indicate towards low ductility and impact toughness at centre. Also it points out that the impact energy is not uniformly getting transmitted to the adjacent regions.

From the post ballistic micro-structural observations (Figures 15-17), large deformations along with shear bands are observed in all the target plates. However, it is seen that on the surface impacted plates, both the shear band and crack formation decrease considerably. Formation of adiabatic shear bands at high strain rates at room temperature has been studied by several investigators [28] [29] [30]. During projectile impact, heat generated by the shear deformation is restricted to a narrow region in which it decreases the material strength and causes instability. Shear band is generated due to this extension of thermo-mechanical instability. The incompatibility of the deformed region increases to accommodate the overall distribution of dissipation energy. This results in cracks in surrounding regions. Hence, it can be inferred that formation of less number of shear bands at the surface of the plate indicates better dissipation of heat generated by the projectile impact. The plastic deformation is better distributed and more homogeneous if shear bands are not formed [31]. It is to be noted that 
both the surface and centre of the plate display moderate and very strong texture, respectively. This has resulted in different properties. Observations of less number of shear bands at plates impacted on the surface, therefore suggest that the heat generated due to projectile impact has dissipated to the surrounding areas effectively due to moderate texture. On the other hand, energy dissipation is non uniform at centre of the plate due to the presence of very strong texture. As a result, surface of the plate displays better ballistic performance than the centre.

The variation in hardness adjacent to the penetration channel is a result of two simultaneously competing processes i.e. annealing and strain hardening effects. Annealing effect caused by rise in temperature after projectile impact and strain hardening caused by severe deformation. Adjacent to the penetration channel, wall temperature rise is high. As a result, the hardness rise is less. Little beyond, annealing effect decreases but strain hardening is still there. This results in the increase in hardness. Eventually, the extent of strain hardening also decreases. Consequently, there is a fall in the hardness curve till it reaches the initial hardness of the plate. In case of surface impacted plates, the extent of deformation is spread over a comparatively larger volume than that of the plates impacted on the centre of the plate. This implies that more volume of the material at the surface is involved in absorbing the kinetic energy of the projectile. This in turn helps the material to absorb the energy in a homogeneous manner. The microhardness results are in accordance with the microstructural observations.

\section{Conclusion}

The different microstructures and textures at surface and centre of the plate result in the anisotropy of the mechanical properties. The weak texture at surface helps the material to absorb the projectile impact energy efficiently and it has led to a better ballistic behaviour of the material. Due to strong texture at the centre of the material, the impact energy gets constricted to a narrow region and felicitates the formation of easy shear bands and a poor ballistic behaviour. Type of texture present in sheet material has strong bearing on both the mechanical and ballistic properties.

\section{Acknowledgements}

The authors wish to acknowledge DRDO, Government of India for financial support and The Director, DMRL for his encouragements. Help rendered by the K.E. Complex team of ATC, DMRL in carrying out the ballistic trials is gratefully acknowledged.

\section{References}

[1] Jena, P.K., Ramanjeneyulu, K., Sivakumar, K. and Bhat, T.B. (2009) Ballistic Studies on Layered Structures. Mater Design, 30, 1922-1931.

https://doi.org/10.1016/j.matdes.2008.09.008 
[2] Demir, T., Übeyli, M. and Yıldırım, R.O. (2008) Investigation on the Ballistic Impact Behavior of Various Alloys against $7.62 \mathrm{~mm}$ Armor Piercing Projectile. Mater Design, 29, 2009-2016. https://doi.org/10.1016/j.matdes.2008.04.010

[3] Gupta, N.K. and Madhu, V. (1997) An Experimental Study of Normal and Oblique Impact of Hard-Core Projectile on Single and Layered Plates. International Journal of Impact Engineering, 19, 395-414. https://doi.org/10.1016/S0734-743X(97)00001-8

[4] Gupta, N.K., Iqbal, M.A. and Sekhon, G.S. (2006) Experimental and Numerical Studies on the Behavior of Thin Aluminum Plates Subjected to Impact by Blunt and Hemispherical-Nosed Projectiles. International Journal of Impact Engineering, 32, 1921-1944. https://doi.org/10.1016/j.ijimpeng.2005.06.007

[5] Millet, J.C.F., Bourne, N.K. and Edwards, M.R. (2004) The Effect of Heat Treatment on the Shock Induced Mechanical Properties of Aluminium Alloy-7017. Scripta Materialia, 51, 967-971. https://doi.org/10.1016/j.scriptamat.2004.07.020

[6] Lee, Y.B., Shin, D.H., Park, K.T. and Nam, W.J. (2004) Effect of Annealing Temperature on Microstructures and Mechanical Properties of a $5083 \mathrm{Al}$ Alloy Deformed at Cryogenic Temperature. Scripta Materialia, 51, 355-359. https://doi.org/10.1016/j.scriptamat.2004.02.037

[7] Oosterkamp, L.D., Ivankovic, A. and Venizelos, G. (2000) High Strain Rate Properties of Selected Aluminium Alloys. Materials Science and Engineering. A, 278, 225-235. https://doi.org/10.1016/S0921-5093(99)00570-5

[8] Borvik, T., Clausen, A.H., Hopperstad, O.S. and Langseth, M. (2004) Perforation of AA5083-H116 Aluminium Plates with Conical-Nose Steel Projectiles-Experimental Study. International Journal of Impact Engineering, 30, 367-384. https://doi.org/10.1016/S0734-743X(03)00072-1

[9] Siva kumar, K., Singh, D. and Bhat, T.B. (2004) Studies on Aluminium Armour Plates Impacted by Deformable and Non-Deformable Projectile. Materials Science Forum, 465-466, 79-84.

[10] Mondal, C., Mishra, B., Jena Pradipta, K., Siva Kumar, K. and Bhat, T.B. (2011) Effect of Heat Treatment on the Behavior of an AA7055 Aluminum Alloy during Ballistic Impact. International Journal of Impact Engineering, 38, 745-754. https://doi.org/10.1016/j.ijimpeng.2011.03.001

[11] Borvik, T., Clausen, A.H., Eriksson, M., Hopperstad, O.S. and Langseth, M. (2005) Experimental and Numerical Study on the Perforation of AA6005-T6 Panels. International Journal of Impact Engineering, 32, 35-64. https://doi.org/10.1016/j.ijimpeng.2005.05.001

[12] Orgorkiewicz, R.M. (1969) Armor for Combat Vehicles. New Armour Materials. Mach Des., 36-42.

[13] Sudhakar, I., Madhu, V., Madhusudan Reddy, G. and Rao, K.S. (2015) Enhancement of Wear and Ballistic Resistance of Armour Grade AA7075 Aluminium Alloy using Friction Stir Processing. Defence Technology, 11, 10-17. https://doi.org/10.1016/j.dt.2014.08.003

[14] Jha, A.K., Shiresha, N., Murty, S.V.S.N., Diwakar, V. and Sreekumar, K. (2005) Ballistic Impact Testing of AA2219 Aluminium Allow Welded Plates and Their Metallurgical Characterization. Indian Journal of Engineering and Materials Sciences, 12, 221-226.

[15] Gu, G., Ye, L., Jiamg, H., Sun, D., Zhang, P. and Zhang, X. (2014) Effects of T9I6 Thermo-Mechanical Process on Microstructure, Mechanical Properties and Ballistic Resistance of 2519A Aluminum Alloy. Transactions of Nonferrous Metals Society of China, 24, 2295-2300. https://doi.org/10.1016/S1003-6326(14)63347-1 
[16] Sullivan, A., Derry, C., Robson, J.D., Horsfall, I. and Prangnell, P.B. (2011) Microstructure Simulation and Ballistic Behaviour of Weld Zones in Friction Stir Welds in High Strength Aluminium 7xxx Plate. Materials Science and Engineering. A, 528, 3409-3422. https://doi.org/10.1016/j.msea.2011.01.019

[17] Mishin, O.V., Bay, B. and Jensen, D.J. (2000) Through Thickness Texture Gradients in Cold-Rolled Aluminum. Metallurgical and Materials Transactions A, 31, 1653-1662. https://doi.org/10.1007/s11661-000-0175-2

[18] Engler, O., Huh, M.Y. and Tomé, C.N. (2000) A Study of Through-Thickness Texture Gradients in Rolled Sheets. Materials Transactions A, 31, 2299-2315. https://doi.org/10.1007/s11661-000-0146-7

[19] Liu, W.C. and Morris, J.G. (2005) Through-Thickness Texture Variation in Cold-Rolled AA 5182 Aluminum Alloy with an Initial $\{001\} 110$ Texture. Materials Transactions A, 36, 1329-1338. https://doi.org/10.1007/s11661-005-0224-y

[20] Jazaeri, H. and Humphreys, F.J. (2004) The Transition from Discontinuous to Continuous Recrystallization in Some Aluminium Alloys: I-The Deformed State. Acta Materialia, 52, 3251-3262. https://doi.org/10.1016/j.actamat.2004.03.031

[21] Mehta, K.K., Mukhopadhyay, P., Mandal, R.K. and Singh, A.K. (2014) Mechanical Properties Anisotropy of Cold-Rolled and Solution-Annealed Ni-Based Hastelloy C-276 Alloy. Metallurgical and Materials Transactions A, 45, 3493-3504. https://doi.org/10.1007/s11661-014-2294-1

[22] Schultz, L.G. (1949) A Direct Method of Determining Preferred Orientation of a Flat Reflection Sample using Geiger Counter X-Ray Spectrometer. Journal of Applied Physics, 20, 1030-1033. https://doi.org/10.1063/1.1698268

[23] Chen, J.Z., Zhen, L., Zhang, B.Y., Cui, Y.X. and Dai, S.L. (2007) Through-Thickness Microstructure, Texture and Strength Gradients in AA 7055 Rolled Plate. Materials Science Forum, 546-549, 957-960. https://doi.org/10.4028/www.scientific.net/MSF.546-549.957

[24] Lang, Y., Cai, Y., Cui, H. and Zhang, J. (2011) Effect of Strain-Induced Precipitation on the Low Angle Grain Boundary in AA7050 Aluminum Alloy. Materials and Design, 32, 4241-4246. https://doi.org/10.1016/j.matdes.2011.04.025

[25] Chang, S.C., Jiang, Q.D., Hu, J.R. and Chen, F.R. (1998) The Texture and Formation of Shear Bands in a Hot Rolled 7050 Aluminium Alloy. Scripta Materialia, 39, 583-588. https://doi.org/10.1016/S1359-6462(98)00200-0

[26] Wingrove, A.L. and Wulff, G.L. (1973) Some Aspects of Target and Projectile Properties on Penetration Behavior. Journal of the Australian Institute of Metals, 18 , 167-172.

[27] Bhat, T.B. (1984) Principles of Armour Design. Transactions of the Indian Institute of Metals, 37, 313-332.

[28] Xue, Q., Meyers, M.A. and Nesterenko, V.F. (2004) Self Organization of Shear Bands in Stainless Steel. Materials Science and Engineering. A, 384, 35-46. https://doi.org/10.1016/j.msea.2004.05.069

[29] Lee, C.G., Lee, Y. and Lee, S. (1995) Observation of Adiabatic Shear Bands Formed by Ballistic Impact in Aluminium-Lithium Alloys. Scripta Materialia, 32, 821-826. https://doi.org/10.1016/0956-716X(95)93208-L

[30] Timothy, S.P. (1987) The Structure of Adiabatic Shear Bands in Metals: A Critical Review. Acta Metallurgica, 35, 301-306. https://doi.org/10.1016/0001-6160(87)90238-0

[31] Korbel, A., Dobrazanski, F. and Richert, M. (1983) Strain Hardening of Aluminum at High Strains. Acta Metallurgica, 31, 293-298. https://doi.org/10.1016/0001-6160(83)90106-2 